\title{
Positive impact of a pre-school-based nutritional intervention on children's fruit and vegetable intake: results of a cluster-randomized trial
}

\author{
Freia De Bock ${ }^{1,2, *}$, Luise Breitenstein ${ }^{1}$ and Joachim E Fischer ${ }^{1}$ \\ ${ }^{1}$ Competence Center for Social Medicine and Occupational Health Promotion, Mannheim Institute of Public \\ Health, Social and Preventive Medicine, University Medicine Mannheim, Heidelberg University, \\ Ludolf-Krehl-Strasse 7-1 1, D-68167 Mannheim, Germany: ${ }^{2}$ Children's Hospital, University Medicine Mannheim, \\ Heidelberg University, Mannheim, Germany
}

Submitted 19 November 2010: Accepted 25 June 2011: First published online 23 August 2011

\begin{abstract}
Objective: To assess the short-term impact of a nutritional intervention aimed at reducing childhood overweight in German pre-school children.

Design: Using a cluster-randomized study design with waiting-list controls, we tested a 6-month intervention administered once weekly by a nutrition expert consisting of joint meal preparation and activities for children and parents such as tasting and preparing nutritious, fresh foods. At baseline, 6 and 12 months, a parent-completed questionnaire assessed fruit and vegetable intakes (primary outcomes) and water and sugared drinks consumption (secondary outcomes). Direct measurement assessed BMI, skinfold thickness and waist-to-height-ratio. An intention-to-treat analysis used random-effects panel regression models to assess the intervention effect, adjusted for each child's age, gender, immigrant background and maternal education.

Setting: Eighteen pre-schools from three south German regions.

Subjects: Healthy children aged 3-6 years.

Results: Three hundred and seventy-seven (80\%) eligible pre-school children participated in the study. Of these, 348 provided sufficient data for analysis. The sample mean age was $4 \cdot 26$ (SD 0.78 ) years; the majority $(53 \cdot 2 \%)$ were boys. Children's fruit and vegetable intakes increased significantly $(P<0.001$ and $P<0 \cdot 05$, respectively); no significant changes in the consumption of water, sugared drinks or anthropometric measurements were noted.

Conclusions: Nutritional interventions in pre-schools have the potential to change eating behaviours in young children, which in the long term might reduce risk for developing overweight.
\end{abstract}

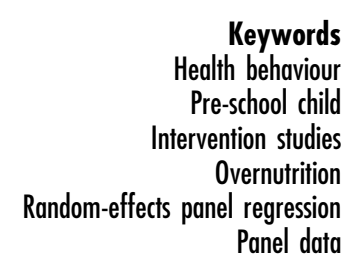

The prevalence of overweight in children has emerged as a public health issue of increasing importance in both developed and developing countries ${ }^{(1)}$. In Europe, for example, the prevalence of overweight in children currently is estimated to be $20 \%$, one-third of whom are obese $^{(2,3)}$. Childhood overweight is defined as BMI equal to or greater than the 90th reference percentile in Europe (International Obesity Taskforce criteria $^{(4)}$ ) or the 95th percentile in the USA (http://www.cdc.gov). Given the high prevalence and the known long-term effects of childhood overweight such as dyslipidaemia, hyperinsulinaemia, hypertension ${ }^{(5-7)}$, persistent overweight in adulthood $^{(8-11)}$ as well as its social and economic consequences $^{(12-15)}$, an urgent need for effective interventions early in childhood has become evident.

Factors that influence a child's weight are partly genetic and partly environmental ${ }^{(16,17)}$. In industrialized societies, environmental factors such as high energy intake paired with physical inactivity can lead to an energy surplus and increased body fat ${ }^{(18)}$. Nutritional surveys from several European countries show consumption trends among 3-year-old children exceeding recommendations for highenergy foods and beverages and failure to meet recommendations for fruits and vegetables ${ }^{(19,20)}$. Changing children's eating behaviour is therefore potentially useful for preventing childhood overweight.

Previous work suggests that eating behaviour in early childhood might be changed more easily while these behavioural patterns are still developing ${ }^{(16,21,22)}$. The preschool setting may be especially appropriate for behavioural interventions ${ }^{(23)}$, as it is among the first in which young children encounter behavioural norms different from those in the home. Given high pre-school attendance rates in several industrialized countries ${ }^{(24,25)}$, 
nutritional interventions conducted in these settings could positively impact the health of many children ${ }^{(26)}$.

Although few published reports of interventions in this area exist, those that do suggest the potential for successfully promoting healthy nutrition in pre-school settings. A questionnaire-based study of 4-6-year-old pre-school children in China, for example, observed a significant decrease in unhealthy dietary behaviours ${ }^{(27)}$, while a Canadian pre-school programme reported significant increases in the frequency of fruit and vegetable intake ${ }^{(28)}$. Other studies conducted in primary and secondary schools, involving older children, provide further evidence that eating behaviour can be effectively modified through school-based nutritional interventions ${ }^{(8,29,30)}$.

Most of these interventions primarily used educational strategies aimed at rising awareness in children ${ }^{(29)}$, parents and teachers. Based on theoretical frameworks of modelling ${ }^{(31)}$ and the general system theory ${ }^{(32)}$, however, involvement of parents, teachers and peers in a participatory way - reaching beyond mere education - might be most effective.

While use of anthropometric outcomes has been infrequently reported in previous evaluations, a single study observed no significant differences in body weight and height-for-age ${ }^{(27)}$. Previous work, however, suggests that higher BMI in children is associated with physiological risk factors and even premature death ${ }^{(33)}$. Therefore, it appears important that nutritional intervention studies incorporate both intermediate behavioural and anthropometric outcomes measures. The aim of the present study was thus to assess the effects of a pre-school-based nutritional intervention on both behavioural outcomes, like children's fruit, vegetable and water consumption, and anthropometric measures.

\section{Methods}

\section{Setting and participants}

The study was set in Baden-Württemberg, a federal state (population nearly 11 million) in south-west Germany with an extensive network of urban and rural pre-schools for 3-6-year-old children, cared for by certified teachers.

Pre-schools were eligible to participate in the study if they were located in one of three predefined regions and had applied to participate in the nutritional intervention module of a state-sponsored health promotion programme 'Komm mit in das gesunde Boot' ('Come aboard the health boat'), with at least fifteen children participating. This programme comprised of two distinct arms was initiated in 2006 to encourage (i) healthy eating behaviour and (ii) physical activity $^{(34)}$ among pre-school children, with the long-term goal of reducing childhood overweight. The current paper focuses on the nutritional intervention. Analyses of the physical activity module's effectiveness are conducted separately with interactions between both modules not assessed.

Twenty-three pre-schools (mean size: forty-eight children) met the above-mentioned criteria with eighteen (78\%) agreeing to participate (see Fig. 1), either with all children (in small pre-schools) or the older children (in larger schools), due to a maximum group size of twenty students per expert. The vast majority of parents (>95\%) consented to their child participating in the programme if the pre-schools had scheduled participation. Children between 3 and 6 years of age attending one of the participating pre-schools and participating in the programme ( $n$ 473) were considered eligible for our study. A total of 377 pre-school children (80\%) were recruited in Autumn 2008 following written informed consent provided by each child's parents; at least one outcome measurement
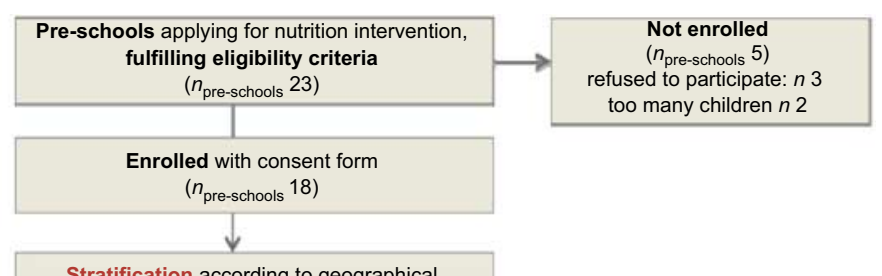

Stratification according to geographical location and socio-economic status Randomization into two study arms ( $n_{\text {pre-schools }}$ 18)
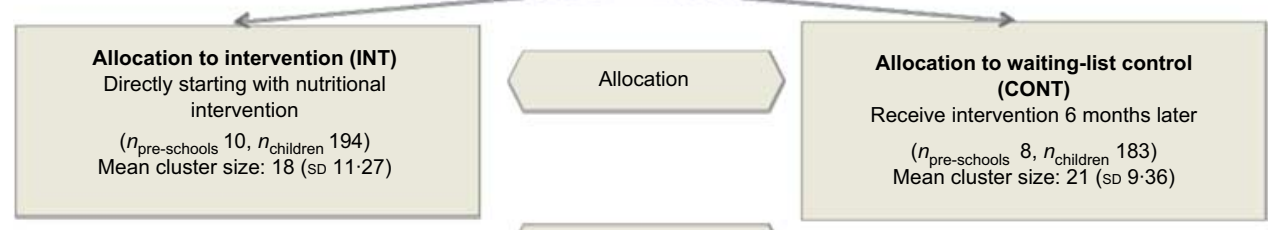

Follow-up

Fig. 1 (colour online) Enrolment, stratification, randomized allocation of pre-schools and resulting number of children in each arm: cluster-randomized trial of a pre-school-based nutritional intervention on children's fruit and vegetable intakes, south Germany 
was obtained on 348 (93\%). The study was approved by the ethical committee of Heidelberg University, Mannheim Medical Faculty.

\section{Study design}

Our study used a cluster-randomized trial design, with natural pre-school-bound clusters of children randomized to either the intervention or the waiting-list control $\operatorname{arm}^{(34)}$. Pre-schools in the waiting-list control arm ( $n_{\text {pre-schools }} 8, n_{\text {children }} 183$ ) received the same intervention 6 months later than the intervention arm ( $n_{\text {pre-schools }} 10$, $\left.n_{\text {children }} 194\right)$. To account for seasonal differences in fruit and vegetable intake, the study was implemented with half of the pre-schools starting in Autumn 2008, the other half in Spring 2009.

As previous research in children has shown differences in eating behaviour ${ }^{(35)}$ and BMI by socio-economic status $(\mathrm{SES})^{(36)}$, we stratified the recruited pre-schools before randomization to balance aggregate pre-school social background and immigrant proportion (see De Bock et al. ${ }^{(34)}$ ).

\section{Intervention - theoretical framework and delivery}

Nutritional interventions in older children have chosen various theoretical frameworks, yet many are based upon the assumptions of Bandura's ${ }^{(31)}$ social learning theory ${ }^{(37-39)}$ or Zajonc's ${ }^{(40)}$ exposure effect ${ }^{(41-43)}$. The theory of social learning suggests that children's eating behaviour evolves from imitating the behaviour they observe in significant others, like parents and peers ${ }^{(17)}$. Thus, for an intervention to be most effective, it may be useful to include parents to modify children's behaviour ${ }^{(44)}$. Zajonc's exposure effect ${ }^{(40)}$ suggests that even very young children are more likely to eat specific foods when these are repeatedly and consistently offered to them ${ }^{(17,45,46)}$. Our nutritional intervention incorporated elements from both theoretical frameworks.

The intervention was delivered by external nutrition experts who participated in intensive $4 \mathrm{~d}$ training sessions covering specific nutritional guidelines for children and basic communication skills. The experts delivered the intervention during fifteen standardized $2 \mathrm{~h}$ nutrition sessions, mostly during pre-school hours, conducted once weekly over a 6-month period with five of these sessions actively involving parents by targeting them alone (discussions on parents' modelling role and nutritional needs of children) or together with their children (Table 1). Intervention activities consisted of familiarizing with different food types and preparation methods as well as cooking and eating meals together in groups of children, teachers and parents. One session additionally focused on healthy drinking behaviours. Pre-school group teachers assisted the external nutrition expert during each session to enable them to sustain intervention-related activities after the study end.

Models for healthy eating within the intervention included: (i) use of nutrition experts; (ii) play acting with 'pirate dolls' used as props enjoying fruit and vegetables;
Table 1 The nutritional intervention, consisting of fifteen $2 \mathrm{~h}$ sessions once weekly over a period of 6 months. Ten modules only targeted children, another five parents and children or parents exclusively

\begin{tabular}{|c|c|}
\hline Involved & Module theme \\
\hline \multirow[t]{7}{*}{ Children } & Fruit and vegetables (two modules) \\
\hline & $\begin{array}{l}\text { Growing crops/food production (two } \\
\text { modules) }\end{array}$ \\
\hline & Food variety in the supermarket \\
\hline & Preparing food \\
\hline & Different eating cultures \\
\hline & How food and drinks are affecting our body \\
\hline & $\begin{array}{l}\text { Importance of water for our body } \\
\text { Common meals }\end{array}$ \\
\hline \multirow[t]{3}{*}{ Parents } & Balanced nutrition \\
\hline & Children's eating behaviour \\
\hline & Sharing our own experiences \\
\hline Parents and children & Preparing fruit and vegetable snacks \\
\hline Fathers and children & Fathers baking with their children \\
\hline
\end{tabular}

(iii) active parental involvement; and (iv) involvement of other pre-school peers. The exposure effect was taken into account by repeatedly offering healthy snacks like fruit and vegetables and water to the children every week.

\section{Process evaluation}

Evaluating an intervention's effectiveness and processes at the same time may aid in understanding why an intervention was effective. Our process evaluation was based upon telephone interviews with the nutrition experts directly involved in intervention delivery. Our assessment used elements $^{(47)}$ of the RE-AIM framework, specifically focusing on reach (proportion of target population participating in intervention), effectiveness and implementation (e.g. fidelity to or adaptation of the intervention schedule and its components and the effort required to organize intervention-related activities within each pre-school setting). Reach was reflected by the proportion of participating children and parents compared with the total number of targeted, eligible and recruited children and parents. Implementation ratings adapted from Glasgow et $a l^{(47)}$ on fidelity to planned intervention delivery, total intervention content covered by the experts, effort to get activities organized and the level of parental commitment were given on an ordinal scale ranging from $0=$ not at all/none to $5=$ completely/ a great deal, separately for parent and children's modules, based upon ratings by the nutrition experts.

\section{Measurements}

Quantitative outcome measurements were obtained before start (baseline) and at 6 and 12 months (sustainability) after baseline. Given a cross-over study design, pre-schools assigned to the waiting-list control arm underwent one additional measurement at 6 months before intervention start. Our choice of outcomes combines both intermediate behavioural and objective health parameters to grasp possible translation of behaviour change into anthropometric changes. 


\section{Parental questionnaire}

The study questionnaire, completed by the child's parents, assessed multiple domains of behaviour including children's eating behaviour and physical activity. Wherever possible, we used items from existing surveys; given limited previous work in this area, however, it was necessary to adapt or create new items to assess specific outcomes. Given the potential inaccuracy of extensive food inventories completed by young children or by parents unable to observe their child during the course of the day, we relied instead on parental report of consumption of specific foods or beverages that reflect general eating behaviour. For the assessment of our primary outcomes, fruit and vegetable intakes, we used items developed by Bayer et al. $^{(48)}$ : 'How many portions (size of a child's hand) of fruit does your child eat at average per day?' and 'How many portions (size of a child's hand) of vegetables does your child eat at average per day?' Responses were given on a 6-point ordinal scale ranging from 'none' to 'more than three portions per day'.

Secondary outcomes included the consumption of water (as assessed by an adaptation of an FFQ item: 'How many [glasses] does your child drink per day ( 1 glass $=$ $200 \mathrm{ml}$ )?') and sugared drinks (using the same item stem with sugared drinks defined as soft drinks, beverages containing juice concentrates, $100 \%$ fruit juice and sugared tea/iced tea). Responses on a 6-point ordinal scale for both items ranged from 'seldom or never' to 'four or more glasses per day'. After identifying consumption in each category, we created a single composite score of sugar-sweetened beverage consumption for each child.

\section{Anthropometry and body composition}

Trained study personnel performed all anthropometric measurements. Height (to the nearest $0 \cdot 1 \mathrm{~cm}$; model Seca 201, Seca Deutschland, Hamburg, Germany) and weight (to the nearest $0 \cdot 1 \mathrm{~kg}$; model Glaswaage Nr. 63685 , Soehnle pharo, Nassau, Germany) were measured following a standardized protocol. BMI was calculated using the standard formula of weight $(\mathrm{kg})$ divided by the square of height $\left(\mathrm{m}^{2}\right)$. Overweight was defined by ageand gender-specific 90th percentile cut-offs of BMI taken from a representative sample of German pre-school children $^{(49)}$.

Waist circumference was measured directly on the skin half-way between the top of the iliac crest and the lower rib $^{(50)}$ with an accuracy of $0.5 \mathrm{~cm}$ using a non-elastic measuring tape (Seca Messband 201; Seca Deutschland) with waist-to-height-ratio (WTHR) calculated as a measure of central body fat ${ }^{(51-53)}$. Total body fat was determined by at least two averaged measurements at the triceps, biceps, subscapular, vertical hip and calf skinfolds using Lange Skin Fold Calipers (Beta Technology, Santa Cruz, CA, USA). These mean measures of all skinfolds (triceps to calf) were summed for each child to yield the outcome 'skinfold sum'(54,55).
The quality of anthropometric measurements was maintained through biannual refresher trainings for study personnel and assessment of inter-rater reliability through duplicate measurement. The mean inter-rater correlation coefficient over all measures taken across all measurement time points was $0 \cdot 87$, suggesting a high level of reliability among study personnel, who were also blinded to group assignment.

\section{Measurement of covariates and confounders}

The analysis was adjusted for confounding factors at the child's level including age, gender ${ }^{(56)}$ SES $^{(57)}$ and immigrant background ${ }^{(58)}$. Sociodemographic information was collected through the parent-completed questionnaire. Immigrant background of each child was determined by parental response to three items: (i) child is a non-German national; (ii) child's parents are native speakers of a language other than German; and (iii) child primarily speaks a language other than German at home ${ }^{(59)}$. Responses (yes $=1 ;$ no $=0$ ) were added to create a final value. The child's SES was estimated using his/her mother's self-report of the highest level of educational attainment as a proxy $^{(60,61)}$. According to the international Standard Classification of Education (ISCED) ${ }^{(62)}$, we defined three categories of maternal education: 'high' = ISCED level 5 or 6 , 'middle' = ISCED level 4 and 'low' = ISCED level 1, 2 or 3 .

\section{Statistical analysis}

The data set comprised up to three measurement points per child. Ordinal scale points included as outcome variables were treated as continuous. Descriptive statistical analysis was performed on all outcome measures and bivariate linear regression analyses reflected the intervention effect.

With $81 \%$ of the children contributing more than one measurement to the data set, the effects of the intervention on the whole sample could be captured using a panel regression analysis. This technique can be useful when data consist of repeated observations in one or more cross-sectional units like individual children ${ }^{(63,64)}$. It allows analysing individual dynamics based upon withinand between-person differences in time, controlling for unobserved heterogeneity.

As our data stemmed from natural pre-school-bound clusters of children, we first determined the extent of clustering. Intraclass correlation coefficients (ICC) on the level of pre-schools were $0 \cdot 016$ and $0 \cdot 014$ for the primary outcomes of fruit intake and vegetable intake, respectively. With an average cluster size of $19 \cdot 5$ children per pre-school, the design effect $(d=1+$ (average cluster size -1$) \times$ ICC $)$ did not exceed 2, allowing us to ignore the issue of clustering in our analyses ${ }^{(65-68)}$.

Next, the panel regression models were built with the intervention effect expressed as change in ordinal scale points. In models for outcomes other than water intake, we were able to use random-effects panel regression since our estimators were unbiased, based on the Hausman ${ }^{(69)}$ 
specification test $\left(\chi^{2}<4 \cdot 5 ; \quad P>0 \cdot 1\right)$. Random-effects estimators generally are more efficient than fixed-effects estimators. Yet, for the analysis of water intake we used a fixed-effects panel regression as the random-effects estimators were biased $\left(\chi^{2}=6 \cdot 60 ; P=0 \cdot 036\right)$. In our initial model, we used panel-robust estimators and adjusted the intervention effects to the time-variant factor age. A second model additionally adjusted for potential confounders including gender, immigrant background and maternal education. A supplemental analysis for the anthropometric outcome variables was performed separately in the subgroup of overweight children.

The study was powered on the primary outcome vegetable intake, for which we expected the smallest clinically relevant effect size, assumed to be 0.05 in the panel regression model. $f^{2}=0.05$ is traditionally considered a small to medium effect size ${ }^{(70)}$. With a power of $0 \cdot 8$, $\alpha=0 \cdot 05 / 3=0 \cdot 0167$ (adjusted for three measurement time points) and accounting for five independent predictors, we determined a minimal sample size of $n$ 332. All statistical analyses were performed with the STATA 10 statistical software package (StataCorp LP, College Station, TX, USA).

\section{Results}

Of the 348 pre-school children (Table 2) providing data, 29.6\% ( $n$ 103) participated in measurements at all three time points, 51.4\% ( $n$ 179) children participated twice and $19 \cdot 0 \%(n$ 66) at one measurement point, with $58.0 \%$ of the children ( $n$ 202) providing both preand post-intervention measurements. The majority of the sample $(53 \cdot 2 \%)$ was boys. Nearly a third $(32 \cdot 4 \%, n 113)$ of all children came from an immigrant background; fifty-seven (16.3\%) and seventy-four (21.2\%) had mothers with low and higher educational levels, respectively. Mean age was $4 \cdot 26$ (SD $0 \cdot 78$ ) years. The proportion of overweight children was $8 \cdot 4 \%{ }^{(49)}$, a figure comparable to German national statistics $(9 \%)^{(71)}$. Gender distribution, immigrant background and maternal educational levels were similar among participants across measurement time points. With the exception of mean age, there were no significant differences in children's characteristics between those providing both pre- and post-intervention measurements compared with the full sample (Table 2).

At baseline, $60 \cdot 0 \%$ and $34 \cdot 6 \%$ of the pre-school children achieved the recommended amounts of at least two portions $(200 \mathrm{~g})$ of fruit and vegetables daily ${ }^{(72)}$, respectively. When comparing only pre-intervention and post-intervention measurements, there was a significant change from baseline in fruit and vegetable intakes (Fig. 2). Specifically, we found a mean increase from baseline of $0 \cdot 17$ points on the 6 -point ordinal scale $(P \leq 0 \cdot 05)$ for fruit consumption frequency and 0.22 points $(P \leq 0 \cdot 01)$ for vegetable consumption, unadjusted for other characteristics.

Table 2 Characteristics of the study participants (in percentage and absolute numbers): children participating in a cluster-randomized trial of a pre-school-based nutritional intervention on fruit and vegetable intakes, south Germany

\begin{tabular}{|c|c|c|c|c|}
\hline \multirow[b]{2}{*}{ Total } & \multicolumn{2}{|c|}{$\begin{array}{c}\text { All study } \\
\text { participants ( } n \text { 348) }\end{array}$} & \multicolumn{2}{|c|}{$\begin{array}{l}\text { Study participants with both pre- and } \\
\text { post-intervention measurementst }(n 202)\end{array}$} \\
\hline & $n$ & $\%$ & $n$ & $\%$ \\
\hline \multicolumn{5}{|c|}{ Contributing to data set by } \\
\hline 1 measurement & 66 & $19 \cdot 0$ & & \\
\hline 2 measurements & 179 & $51 \cdot 4$ & & \\
\hline 3 measurements & 103 & $29 \cdot 6$ & & \\
\hline \multicolumn{5}{|l|}{ Gender } \\
\hline Female & 163 & $46 \cdot 8$ & 89 & $44 \cdot 0$ \\
\hline Male & 185 & $53 \cdot 1$ & 113 & $55 \cdot 9$ \\
\hline Missing & 0 & $0 \cdot 0$ & & \\
\hline \multicolumn{5}{|l|}{ Age (years) } \\
\hline 3 & 56 & $16 \cdot 0$ & 21 & $10 \cdot 4$ \\
\hline 4 & 159 & $45 \cdot 6$ & 101 & $50 \cdot 0$ \\
\hline 5 & 117 & $33 \cdot 6$ & 68 & $33 \cdot 6$ \\
\hline 6 & 16 & $4 \cdot 6$ & 12 & $5 \cdot 9$ \\
\hline Missing & 0 & $0 \cdot 0$ & & \\
\hline \multicolumn{5}{|c|}{ Immigrant background } \\
\hline Without & 228 & $65 \cdot 5$ & 141 & $69 \cdot 8$ \\
\hline With & 113 & $32 \cdot 4$ & 61 & $30 \cdot 2$ \\
\hline Missing & 7 & $2 \cdot 0$ & 0 & 0.0 \\
\hline \multicolumn{5}{|c|}{ Maternal educational levelł } \\
\hline Low & 57 & $16 \cdot 3$ & 34 & $16 \cdot 8$ \\
\hline Middle & 194 & $55 \cdot 7$ & 125 & $61 \cdot 8$ \\
\hline High & 74 & $21 \cdot 2$ & 40 & $19 \cdot 8$ \\
\hline Missing & 23 & $6 \cdot 6$ & 3 & $1 \cdot 4$ \\
\hline
\end{tabular}

tParticipants with both pre- and post-intervention measurements had a higher mean age $(P \leq 0.01)$; all other differences were non-significant $(P>0.05)$. Significance levels quoted are two-sided.

‡Maternal education level was defined according to the International Standard Classification of Education (ISCED): 'high' = ISCED level 5 or 6; 'middle' = ISCED level 4; 'low' = ISCED level 1, 2 or 3. 

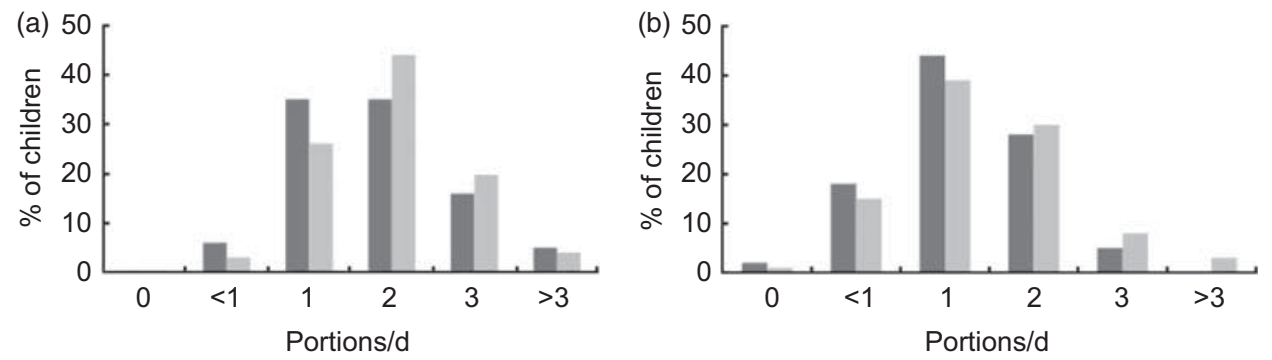

Fig. 2 Children's fruit (a) and vegetable (b) intakes before ( $\square$ ) and after ( $\square$ ) the pre-school-based nutritional intervention, indicated as the percentage of children distributed across intake categories measured as portions (a child's hand full) per day. Data presented include only children with both pre- and post-intervention measurements $(n$ 202, see Table 2)

Table 3 The impact of the intervention on fruit and vegetable intakest using random-effects panel analysis, adjusted for age (model 1a/2a) as well as gender, immigrant background and maternal educational level (model 1b/2b): pre-school children, south Germany

\begin{tabular}{|c|c|c|c|c|}
\hline \multirow[b]{2}{*}{ Variable } & \multicolumn{2}{|c|}{ Change in fruit intake } & \multicolumn{2}{|c|}{ Change in vegetable intake } \\
\hline & Model 1a & Model $1 \mathrm{~b}$ : with control variables & Model 2a & Model $2 \mathrm{~b}$ : with control variables \\
\hline Intervention & $0 \cdot 2162^{\star \star \star}$ & $0 \cdot 2263^{\star \star \star}$ & $0 \cdot 1495^{\star}$ & $0 \cdot 1519^{\star}$ \\
\hline Age (years) & -0.0065 & -0.0071 & 0.0041 & 0.0039 \\
\hline Gender‡ & & 0.0873 & & -0.0061 \\
\hline Immigrant background§ & & $0 \cdot 1092$ & & $0 \cdot 1517$ \\
\hline High maternal education $\|$ & & $0 \cdot 2458$ & & $0.3779^{*}$ \\
\hline Middle maternal education $\|$ & & $0 \cdot 2077$ & & $0 \cdot 3331^{*}$ \\
\hline Constant & $4 \cdot 1479^{\star \star \star}$ & $3 \cdot 8279^{\star \star \star}$ & $2 \cdot 9812^{\star \star \star}$ & $2 \cdot 6522^{\star \star \star}$ \\
\hline Wald $\chi^{2} / F$ test & $13 \cdot 74^{\star \star}$ & $18 \cdot 77^{\star \star}$ & $10 \cdot 05^{\star}$ & $19 \cdot 72^{\star \star}$ \\
\hline$R_{\text {within }}^{2}$ & 0.0331 & 0.0317 & 0.0365 & 0.0361 \\
\hline$n$ & 348 & 325 & 347 & 325 \\
\hline$N$ & 730 & 702 & 726 & 699 \\
\hline
\end{tabular}

$n$, number of children contributing measurements; $N$, number of measurements included in the analysis.

Level of two-sided significance: ${ }^{\star} P \leq 0.05,{ }^{* \star} P \leq 0.01,{ }^{\star * \star} P \leq 0.001$.

tDaily fruit and vegetable intakes as measured in child 'hand' portions on a 6-point ordinal scale, ranging from 'none' to 'more than three'.

‡Reference category: girls.

§Reference category: children without immigrant background.

IMaternal education level was defined according to the international Standard Classification of Education (ISCED): 'high' = ISCED level 5 or 6; 'middle' = ISCED level 4; 'low' = ISCED level 1, 2 or 3. Reference category: low maternal education.

A change of 1 on the 6-point ordinal scale approximates one portion difference (size of a child's hand).

In the random-effects panel analysis including all measurements (Table 3) and controlling for age, we found an increase of $0 \cdot 22$ points on the ordinal scale of fruit consumption compared with consumption before intervention ('within-child comparison') and compared with children not receiving the intervention ('between-child comparison'; $P=0.027)$. Participation in the intervention was also associated with a change in vegetable consumption $(P=0 \cdot 027)$ : we found an increase of $0 \cdot 15$ points on the ordinal scale in vegetable intake (also based upon 'within-child comparison' and 'between-child comparison'). After adjusting for gender, immigrant background and maternal education, regression coefficients for the intervention effect were slightly higher and remained statistically significant for fruit $(0 \cdot 23$; $P=0.001)$ and vegetable $(0 \cdot 15 ; P=0 \cdot 027)$ consumption. These estimators refer to the general intervention effect. Six-month and 12-month measurement points were not differentiated because we only had 12-month data for $18.9 \%$ of pre-schools.
The intervention did not have significant effects on daily water intake or the consumption of high-energy drinks (data not presented). We also found no significant intervention effect on BMI, WTHR or skinfold sum. In the subgroups of overweight and obese children ( $n 18$ with pre- and post-term measurements), bivariate analyses also showed no significant effect of the intervention on BMI, WTHR and skinfold sum. A multivariate analysis adjusted for age was not possible due to the small size of these subgroups.

\section{Process evaluation}

On average, $23 \cdot 1$ (SD $12 \cdot 1)$ children participated regularly in the lessons, with 16.5 (SD 9.5) parents present at the parents' only and parent and children's sessions. In sum, $99 \%$ and $69 \%$ of the recruited children and parents participated, representing $47 \cdot 8 \%$ and $68 \cdot 3 \%$ reach into the target population (recruited and non-recruited) for children and parents, respectively (http://www.re-aim.org/ tools/calculations/use-the-reach-calculator.aspx). For both parent and children's modules and all pre-schools, the 
implementation rate was high with all modules delivered completely $(5 \cdot 0 / 5)$; no session was cancelled. Intervention fidelity was high with the majority of interventions delivered as planned (ratings $4 \cdot 4(\mathrm{SD} 0 \cdot 5)$ and $4 \cdot 2(\mathrm{SD} 0 \cdot 3)$ on 5-point ordinal scale for parent and children's modules, respectively). Those responsible for administering the intervention reported expected seasonal adaptations of the activities like a delay in seed sowing related to the weather. Parental and teacher commitment was rated high $(3.8(\mathrm{SD} 0 \cdot 8)$ and $4 \cdot 2(\mathrm{SD} 1.5)$, respectively). Some experts also related that parents sought more counselling after the sessions ended. The teachers were mostly regarded as very helpful and committed by the nutrition experts, with the amount of effort required to facilitate programme implementation rated as 'low' (2.0 (SD 1.6) out of 5 for both children's and parent modules).

\section{Discussion}

The pre-school-based nutritional intervention arm of the programme significantly increased fruit and vegetable intakes in our sample by around $0 \cdot 23$ and $0 \cdot 15$ portions daily (portion $=$ size of a child's hand representing about $100 \mathrm{~g}$ ), respectively. Although this change appears to be rather small on an individual scale, it is consistent with an increase of $6 \%$ for both fruit and vegetable consumption in the whole sample and therefore might represent a relevant change on population level. According to a Norwegian study reported by Bere et $a l^{(73)}$, a small increase of $2.5 \mathrm{~g}$ of fruit and vegetables daily over lifetime makes e.g. school fruit programmes cost-effective.

Our short-term findings are generally consistent with previous studies in older children: evaluations of schoolbased nutrition programmes in older children showed increases in fruit and vegetable intake $\mathrm{e}^{(8,28-30,74)}$. Middle- to long-term increases are mostly reported in portions per day, ranging from about 0.09 and 0.07 more portions in fruit and vegetables, respectively ${ }^{(74)}$, to $0 \cdot 28$ portions of fruit and vegetables $^{(75)}$, or $10 \%$ daily increases in consumption of fruit ${ }^{(76)}$. The $0 \cdot 23$ and $0 \cdot 15$ portion increases in our preschool study thus are comparable with previous evidence on intervention effects in older children. Some previous intervention studies could also show significant increases in non-primary target foods ${ }^{(28,77)}$. In our pre-school sample, we could not detect any significant change in water or sugar-sweetened drinks consumption. This could be due to the intervention design, which focused more on fruit and vegetable exposure and on testing new foods than on the consumption of drinks. Furthermore, sugar-sweetened drinks consumption in our sample was already at a very low level before the intervention commenced.

A change in eating behaviour might be viewed as an intervention success, even without an observable change in anthropometric parameters. Increased fruit and vegetable intake generally indicates a nutritional pattern characterized by less refined foods and a more balanced nutrition $^{(78)}$. Such healthy nutritional patterns have been shown to lead to a definite yet delayed decrease of BMI and body fat in adults and adolescents, especially if maintained over a longer period ${ }^{(79,80)}$. This suggests that our intervention might still be effective in reducing the prevalence of childhood overweight over the long term, even if it cannot be demonstrated in the current study with a relatively short period of follow-up.

By our process evaluation, we observed that $99 \%$ and $69 \%$ of the recruited children and parents, respectively, were reached by the intervention. This points to the potential importance of this setting for interventions, especially because a vast majority of children attend pre-schools in developed Western countries ${ }^{(24,25)}$. Social learning theory also underlines the value of engaging individuals within and outside the family with potential influence on the development of behaviours and behavioural norms.

Interventions targeting multiple settings and combining healthy nutrition and physical activity promotion have successfully changed anthropometric parameters in older children ${ }^{(81,82)}$. In contrast, nutritional interventions in preschool children could not improve body composition measures, with only very few studies including anthropometric data as outcome variables ${ }^{(27)}$ at all. Even if our short-term findings are consistent with these previous results, our analysis should be repeated including the sustainability measurements from all pre-schools to come to a final conclusion. By the time of reporting, sustainability measurement data from only $18.9 \%$ of pre-schools were available.

Similar to previous work conducted in controlled laboratory settings involving older children and adults ${ }^{(37,39,45,83-86)}$, the exposure effect reflected in our programme suggests that pre-school interventions can have a positive impact on eating behaviour of younger children. Other studies in school-aged children have shown that children's knowledge about nutrition may be improved and their preferences concerning food also changed by nutritional interventions $^{(8,28-30)}$. Although we did not collect comparable data given concerns about the reliability of self-reports in preschool children, we observed parental report of an increase in fruit and vegetable consumption after the intervention. It is unclear whether this finding reflects a direct effect on children's nutritional behaviour or an indirect, beneficial effect on parental knowledge and practice.

The present study has a number of strengths. First, on an international scale, to our knowledge it is one of very few studies evaluating the impact of nutritional interventions in pre-schools ${ }^{(87,88)}$. This is an important research gap, as especially the pre-school period should be viewed as a window of opportunity for establishing healthy nutritional behaviours ${ }^{(5,23,26,45)}$. Second, the current study used objective anthropometric outcomes in addition to self-reported behavioural outcomes. This allows differentiation between behavioural and body 
compositional changes in the children, yet with the anthropometric parameters left unaffected by the intervention. A third strength concerns the theoretical underpinnings of the intervention: with parents playing a substantial role in influencing health behaviours of young children, their inclusion into the intervention may have been an essential precondition for an intervention success ${ }^{(44)}$. In our intervention, a third of the intervention units were delivered to parents only or parents and children instead of children only, and thereby a majority of the parental population could be reached. By this approach, the programme applied a general system theory-based approach $^{(32)}$ linking children, preschool teachers and parents to change pre-school curricula.

Despite these strengths, the study also has several limitations. First, children were sampled from pre-schools that applied for a nutritional intervention, possibly resulting in limited generalizability. Second, in the current analysis, we did not have sustainability measurements from all participating pre-schools. Third, despite the calculation of a minimal sample size of 332, we only had 202 children providing both pre- and post-intervention measurements. Our analysis thus may have been underpowered for detecting changes in anthropometric outcomes or water and sugar-sweetened drinks consumption. Fourth, we evaluated only a limited number of behavioural outcomes. The intervention thus could have changed other eating behaviours, without the study design being able to detect these changes. Last, we did not measure nutritional intake directly, but focused instead on dietary patterns. Although dietary patterns are known to correlate quite well with nutrient intake ${ }^{(89)}$, a food diary or daily weighing approach might have resulted in more accurate data, but was not considered feasible in this sample or study setting.

\section{Conclusions}

The present study demonstrates a significant increase in children's fruit and vegetable intake following a 6-month nutritional intervention in south German pre-schools. Fruit and vegetables are important components of a balanced nutrition $^{(78)}$. Although we were unable to demonstrate an effect of our intervention on anthropometric measures after 6 months, we nevertheless anticipate that increased fruit and vegetable intake over a longer time period might eventually lead to a change in anthropometric features. Future studies evaluating interventions might wish to include long-term effectiveness and sustainability measurements, investigating whether behavioural change through interventions eventually leads to health-relevant changes in anthropometric data.

\section{Acknowledgements}

This work was supported by a grant from the BadenWürttemberg Stiftung. F.D.B. is supported by the European
Social Fund and by the Ministry of Science, Research and the Arts Baden-Württemberg. The authors confirm that they do not have any conflict of interest. Author contributions were as follows. F.D.B.: conception and design of the study, interpretation of data, drafting and revising the manuscript; L.B.: analysis of data, drafting the manuscript; J.F.: conception and design of the study, grant writing. The authors thank the parents, children, families and pre-schools for their cooperation. They also sincerely thank David Litaker, MD, PhD (Departments of Medicine, Epidemiology and Biostatistics, Case Western Reserve University, Cleveland, OH, USA) for his very detailed and thorough review of the manuscript and Professor Dr Josef Brüderl (Department of Sociology, Mannheim University, Mannheim, Germany) for his support with panel analysis.

\section{References}

1. Wilkinson KM (2008) Increasing obesity in children and adolescents: an alarming epidemic. JAAPA 21, 31-36.

2. Troiano RP \& Flegal KM (1998) Overweight children and adolescents: description, epidemiology, and demographics. Pediatrics 101, 497-504.

3. Branca F, Nikogosian H \& Lobstein T (2006) The Challenge of Obesity in the WHO European Region and the Strategies for Response. Copenhagen: WHO.

4. Dietz WH \& Bellizzi MC (1999) Introduction: the use of body mass index to assess obesity in children. Am J Clin Nutr 70, 123-125.

5. Reilly JJ, Methven E, McDowell ZC et al. (2003) Health consequences of obesity. Arch Dis Child 88, 748-752.

6. Wirth A (2008) Adipositas. Ätiologie, Folgekrankheiten, Diagnostik, Therapie. Heidelberg: Springer.

7. Freedman DS, Dietz WH, Srinivasan SR et al. (1999) The relation of overweight to cardiovascular risk factors among children and adolescents: the Bogalusa Heart Study. Pediatrics 103, 1175-1182.

8. Friel S, Kelleher C, Campbell P et al. (1999) Evaluation of the Nutrition Education at Primary School (NEAPS) programme. Public Health Nutr 2, 549-555.

9. Singh AS, Mulder C, Twisk JW et al. (2008) Tracking of childhood overweight into adulthood: a systematic review of the literature. Obes Rev 9, 474-488.

10. Nader PR, O'Brien M, Houts R et al. (2006) Identifying risk for obesity in early childhood. Pediatrics 118, 594-601.

11. Must A (2003) Does overweight in childhood have an impact on adult health? Nutr Rev 61, 139-142.

12. Gortmaker SL, Must A, Perrin JM et al. (1993) Social and economic consequences of overweight in adolescence and young adulthood. $N$ Engl J Med 329, 1008-1012.

13. Wang SS, Brownell KD \& Wadden TA (2004) The influence of the stigma of obesity on overweight individuals. Int $J$ Obes Relat Metab Disord 28, 1333-1337.

14. Strauss RS \& Pollack HA (2003) Social marginalization of overweight children. Arch Pediatr Adolesc Med 157, 746-752.

15. Sargent JD \& Blanchflower DG (1994) Obesity and stature in adolescence and earnings in young adulthood. Analysis of a British birth cohort. Arch Pediatr Adolesc Med 148, 681-687.

16. Birch LL (1998) Development of food acceptance patterns in the first years of life. Proc Nutr Soc 57, 617-624.

17. Wardle J \& Cooke L (2008) Genetic and environmental determinants of children's food preferences. Br J Nutr 99, Suppl. 1, 15-21. 
18. Anderson PM \& Butcher KE (2006) Childhood obesity: trends and potential causes. Future Child 16, 19-45.

19. Mensink G, Kleiser C \& Richter A (2007) Lebensmittelverzehr bei Kindern und Jugendlichen in Deutschland. Ergebnisse des Kinder- und Jugendsurveys (KIGGS). Bundesgesundheitsbl Gesundheitsforsch Gesundheitsschutz 50, 609-623.

20. Yngve A, Wolf A, Poortvliet E et al. (2005) Fruit and vegetable intake in a sample of 11 -year-old children in 9 European countries: The Pro Children Cross-sectional Survey. Ann Nutr Metab 49, 236-245.

21. Zwiauer KF (2000) Prevention and treatment of overweight and obesity in children and adolescents. Eur J Pediatr 159, Suppl. 1, 56-68.

22. Oerter R (2002) Kindheit. In Entwicklungspsychologie. Ein Lebrbuch, pp. 209-258 [R Oerter and L Montada, editors]. Weinheim: Beltz.

23. Rummel C (2001) Projektbeispiele zur Ernährungserziehung im Bereich Kindergarten. In Ernährungsziele unserer Gesellschaft [Bundesforschungsanstalt für Ernährung, editor]. Karlsruhe: Bundesforschungsanstalt für Ernährung.

24. National Institute for Early Education (2004) Preschool attendance reaches new highs, but some are still left behind. NIEER Preschool Policy Matters 2, issue 4; available at http://nieer.org/psm/index.php?article $=74$

25. European Primary Schools Association (1995) Preschool Education in the EU: Current Thinking and Provision. Luxembourg: Office for Official Publications of the European Communities.

26. Story M, Kaphingst KM \& French S (2006) The role of child care settings in obesity prevention. Future Child 16, 143-168.

27. Hu C, Ye D, Li Y et al. (2009) Evaluation of a kindergartenbased nutrition education intervention for pre-school children in China. Public Health Nutr 13, 253-260.

28. Cason KL (2001) Evaluation of a preschool nutrition education program based on the theory of multiple intelligences. J Nutr Educ 33, 161-164.

29. Muth ND, Chatterjee A, Williams D et al. (2008) Making an IMPACT: effect of a school-based pilot intervention. $N C$ Med J 69, 432-440.

30. Anderson AS, Porteous LE, Foster E et al. (2005) The impact of a school-based nutrition education intervention on dietary intake and cognitive and attitudinal variables relating to fruits and vegetables. Public Health Nutr 8 , 650-656.

31. Bandura A (editor) (1974) Die analyse von Modellierungsprozessen. In Lernen am Modell, pp. 9-67. Stuttgart: Klett.

32. Bertalanffy L (1968) General System Theory: Foundations, Developments, Applications. New York: George Braziller.

33. Franks PW, Hanson RL, Knowler WC et al. (2010) Childhood obesity, other cardiovascular risk factors, and premature death. N Engl J Med 362, 485-493.

34. De Bock F, Fischer JE, Hoffmann K et al. (2010) A participatory parent-focused intervention promoting physical activity in preschools: design of a cluster-randomized trial. BMC Public Health 10, 49.

35. Kolip P (2004) Influence of gender and social inequality on nutrition and overweight in children and adolescents. Bundesgesundheitsbl Gesundheitsforsch Gesundheitsschutz 47, 235-239.

36. Kleiser C, Schaffrath Rosario A, Mensink GB et al. (2009) Potential determinants of obesity among children and adolescents in Germany: results from the cross-sectional KiGGS Study. BMC Public Health 9, 46.

37. Lowe CF, Horne PJ, Tapper K et al. (2004) Effects of a peer modelling and rewards-based intervention to increase fruit and vegetable consumption in children. Eur J Clin Nutr $\mathbf{5 8}$, $510-522$.

38. Rinderknecht K \& Smith C (2004) Social cognitive theory in an after-school nutrition intervention for urban Native American youth. J Nutr Educ Behav 36, 298-304.
39. Horne PJ, Tapper K, Lowe CF et al. (2004) Increasing children's fruit and vegetable consumption: a peer-modelling and rewards-based intervention. Eur J Clin Nutr 58, 1649-1660.

40. Zajonc RB (1968) Attitudinal effects of mere exposures. J Pers Soc Psychol 9, 1-27.

41. Perry CL, Mullis RM \& Maile MC (1985) Modifying the eating behavior of young children. J Sch Health 55 , 399-402.

42. Loewen R \& Pliner P (1999) Effects of prior exposure to palatable and unpalatable novel foods on children's willingness to taste other novel foods. Appetite 32, 351-366.

43. Sullivan S \& Birch L (1990) Pass the sugar, pass the salt: experience dictates preference. Dev Psychol 26, 546-551.

44. Lindsay AC, Sussner KM, Kim J et al. (2006) The role of parents in preventing childhood obesity. Future Child 16, 169-186.

45. Birch LL, McPhee L, Shoba BC et al. (1987) What kind of exposure reduces children's food neophobia? Looking vs. tasting. Appetite 9, 171-178.

46. Cooke L (2007) The importance of exposure for healthy eating in childhood: a review. J Hum Nutr Diet 20, 294-301.

47. Glasgow RE, Edwards LL, Whitesides H et al. (2009) Reach and effectiveness of DVD and in-person diabetes selfmanagement education. Chronic Illn 5, 243-249.

48. Bayer O, von Kries R, Strauss A et al. (2009) Short- and midterm effects of a setting based prevention program to reduce obesity risk factors in children: a cluster-randomized trial. Clin Nutr 28, 122-128.

49. Kromeyer-Hauschild K, Wabitsch M, Kunze D et al. (2001) Perzentile für den Body-mass-Index für das Kindes- und Jugendalter unter Heranziehung verschiedener deutscher Stichproben. Monatsschr Kinderheilkd 149, 807-812.

50. Stolzenberg H, Kahl H \& Bergmann KE (2007) Körpermaße bei Kindern und Jugendlichen in Deutschland. Ergebnisse des Kinder- und Jugendgesundheitssurveys (KiGGS). Bundesgesundheitsbl Gesundheitsforsch Gesundheitsschutz 50, 659-669.

51. Roswall J, Bergman S, Almqvist-Tangen G et al. (2009) Population-based waist circumference and waist-to-height ratio reference values in preschool children. Acta Paediatr 98, 1632-1636.

52. Ashwell M (2009) Obesity risk: importance of the waist-toheight ratio. Nurs Stand 23, 49-54.

53. Nambiar S, Truby H, Abbott RA et al. (2009) Validating the waist-height ratio and developing centiles for use amongst children and adolescents. Acta Paediatr 98, 148-152.

54. Freedman DS, Wang J, Ogden CL et al. (2007) The prediction of body fatness by BMI and skinfold thicknesses among children and adolescents. Ann Hum Biol 34, 183-194.

55. Eisenmann JC, Heelan KA \& Welk GJ (2004) Assessing body composition among 3- to 8-year-old children: anthropometry, BIA, and DXA. Obes Res 12, 1633-1640.

56. Anderson SE, Economos CD \& Must A (2008) Active play and screen time in US children aged 4 to 11 years in relation to sociodemographic and weight status characteristics: a nationally representative cross-sectional analysis. BMC Public Health 8, 366.

57. Muller MJ, Koertzinger I, Mast M et al. (1999) Physical activity and diet in 5 to 7 years old children. Public Health Nutr 2, 443-444.

58. Kuepper-Nybelen J, Lamerz A, Bruning N et al. (2005) Major differences in prevalence of overweight according to nationality in preschool children living in Germany: determinants and public health implications. Arch Dis Child 90, 359-363.

59. Schenk L, Bau AM, Borde T et al. (2006) A basic set of indicators for mapping migrant status. Recommendations for epidemiological practice. Bundesgesundheitsbl Gesundheitsforsch Gesundheitsschutz 49, 853-860. 
60. Ball K, Cleland VJ, Timperio AF et al. (2009) Socioeconomic position and children's physical activity and sedentary behaviors: longitudinal findings from the CLAN study. J Phys Act Health 6, 289-298.

61. Semmler C, Ashcroft J, van Jaarsveld CH et al. (2009) Development of overweight in children in relation to parental weight and socioeconomic status. Obesity (Silver Spring) 17, 814-820.

62. United Nations Educational, Scientific and Cultural Organization (1997) International Standard Classification of Education, ISCED 1997. http://www.unesco.org/education/ information/nfsunesco/doc/isced_1997.htm (accessed September 2010).

63. Allison PD (1994) Using panel data to estimate the effects of events. Sociol Method Res 23, 174-199.

64. Halaby CN (2004) Panel models in sociological research: theory into practice. Annu Rev Sociol 30, 507-544.

65. University of California at Los Angeles, Academic Tchnology Services (2010) Analyzing correlated (clustered) data. http:// www.ats.ucla.edu/stat/stata/Library/cpsu.htm (accessed September 2010).

66. Hox JJ (1998) Multilevel modeling: when and why. In Classification, Data Analysis and Data Highways, pp. 147-154 [I Balderjahn, R Mathar and M Schader, editors]. New York: Springer.

67. Moss S (2008) When to apply multi-level modelling. http://www.psych-it.com.au/Psychlopedia/article.asp?id = 225 (accessed September 2010).

68. Muthen BO \& Satorra A (1995) Complex sample data in structural equation modelling. Sociol Methodol 25, 267-316.

69. Hausman JA (1978) Specification tests in econometrics. Econometrica 46, 1251-1271.

70. Cohen J (1988) Statistical Power Analysis for the Behavioral Sciences. Hillsdale, NJ: Lawrence Erlbaum Associates.

71. Kurth B \& Schaffrath Rosario A (2007) The prevalence of overweight and obese children and adolescents living in Germany. Results of the German Health Interview and Examination Survey for Children and Adolescents (KiGGS). Bundesgesundheitsbl Gesundheitsforsch Gesundheitsschutz 50, 736-743.

72. Alexy U, Klausen K \& Kersting M (2008) Die Ernährung gesunder Kinder und Jugendlicher nach dem Konzept der optimierten Mischkost. Ernährungsumschau 55, 168-177.

73. Bere E, Veierod MB, Skare O et al. (2007) Free school fruit - sustained effect three years later. Int J Behav Nutr Phys Act $\mathbf{4}, 5$.

74. Reinaerts E, Crutzen R, Candel M et al. (2008) Increasing fruit and vegetable intake among children: comparing long-term effects of a free distribution and a multicomponent program. Health Educ Res 23, 987-996.
75. Hoffman JA, Thompson DR, Franko DL et al. (2011) Decaying behavioral effects in a randomized, multi-year fruit and vegetable intake intervention. Prev Med 52, $370-375$

76. Siega-Riz AM, El Ghormli L, Mobley C et al. (2011) The effects of the HEALTHY study intervention on middle school student dietary intakes. Int J Behav Nutr Phys Act 8, 7 .

77. Horne PJ, Greenhalgh J, Erjavec M et al. (2011) Increasing pre-school children's consumption of fruit and vegetables. A modelling and rewards intervention. Appetite 56, 375-385.

78. Alexy U, Clausen K \& Kersting M (2008) Die Ernährung gesunder Kinder und Jugendlicher nach dem Konzept der Optimierten Mischkost. Ernährungsumschau 3, 168-175.

79. Tohill BC, Seymour J, Serdula M et al. (2004) What epidemiologic studies tell us about the relationship between fruit and vegetable consumption and body weight. Nutr Rev 62, 365-374.

80. Buijsse B, Feskens EJ, Schulze MB et al. (2009) Fruit and vegetable intakes and subsequent changes in body weight in European populations: results from the project on Diet, Obesity, and Genes (DiOGenes). Am J Clin Nutr 90, 202-209.

81. Taylor RW, McAuley KA, Barbezat W et al. (2008) Two-year follow-up of an obesity prevention initiative in children: the APPLE project. Am J Clin Nutr 88, 1371-1377.

82. Müller MJ, Asbeck I, Mast M et al. (2001) Prevention of obesity - more than an intention. Concept and first results of the Kiel Obesity Prevention Study (KOPS). Int J Obes Relat Metab Disord 25, Suppl. 1, S66-S74.

83. Pliner P, Pelchat M \& Grabski M (1993) Reduction of neophobia in humans by exposure to novel foods. Appetite 20, 111-123.

84. Hobden K \& Pliner P (1995) Effects of a model on food neophobia in humans. Appetite 25, 101-113.

85. Hendy HM (2002) Effectiveness of trained peer models to encourage food acceptance in preschool children. Appetite 39, 217-225.

86. Forestell CA \& Mennella JA (2007) Early determinants of fruit and vegetable acceptance. Pediatrics 120, 1247-1254.

87. Jebb SA \& Lambert J (2000) Overweight and obesity in European children and adolescents. Eur J Pediatr 159, Suppl. 1, S2-S4.

88. Campbell KJ \& Hesketh KD (2007) Strategies which aim to positively impact on weight, physical activity, diet and sedentary behaviours in children from zero to five years. A systematic review of the literature. Obes $\operatorname{Rev} \mathbf{8}, 327-338$.

89. Roman-Vinas B, Ribas Barba L, Ngo J et al. (2009) Validity of dietary patterns to assess nutrient intake adequacy. Br J Nutr 101, Suppl. 2, S12-S20. 